\title{
EL RECURSO DE AGRAVIO CONSTITUCIONAL, PRECEDENTE FRANCISCA VÁSQUEZ ROMERO (STC 009787-2014-PA/TC). ¿UN NUEVO MODELO?*
}

\author{
The Constitutional Tort Action, Vásquez Romero Francisca \\ precedent (STC 009787-2014-PA/TC). A new model?
}

Omar Sumaria Benavente**

Pontificia Universidad Católica del Perú

\section{Resumen}

El autor reflexiona sobre la modificación del régimen del proceso constitucional de amparo a raíz de la dación del precedente recaído en el caso de Francisca Vásquez Romero, además analiza el soporte jurisdiccional para la atención del ejercicio de dicha garantía constitucional.

Palabras clave: Proceso constitucional de amparo; precedente vinculante; supremacía constitucional; jurisdicción ordinaria; jurisdicción constitucional.

\section{Abstract}

The author reflects on the regime of amendment of the writ of amparo process as result of the relapsed precedent emission in the Francisca Vásquez Romero case, besides analyzes the jurisdictional support for the attention of the course of that Constitutional Guarantee.

Keywords: The writ of amparo, binding precedent, constitutional supremacy, ordinary jurisdiction; constitutional jurisdiction.

* Artículo basado en la ponencia dictada en el I Congreso Internacional de Derecho Procesal y Arbitraje, organizado por la Facultad de Derecho de la Universidad Continental, en la ciudad de Huancayo del 2 al 5 de setiembre de 2015.

** Abogado por la Pontificia Universidad Católica del Perú. Maestría en Derecho Procesal por la Universidad Nacional de Rosario, Argentina. Doctorando en Derecho Procesal Contemporáneo por la Universidad de Medellín, Colombia. Vicepresidente del Instituto Iberoamericano de Derecho Procesal, integrante de la Interamerican Bar Association, International Association of Procedural Law, International Conference of Evidence Law and Science Evidence, Instituto Panamericano de Derecho Procesal, Instituto Vasco de Derecho Procesal, Instituto Colombo Venezolano de Derecho Procesal. 
He postulado en trabajos anteriores al proceso como un espacio en el que se encuentra lo social y lo jurídico ${ }^{1}$ y a través del cual se otorga un significado cultural jurídico a las conductas de las personas ${ }^{2}$, además se resuelven las dicotomías relacionales sociales básicas ${ }^{3}$. Cualquier figura, toda noción, aun las tradicionalmente estimadas como estáticas, serán solo datos procesales si no quedan vinculadas por la idea fundamental del dinamismo, a través de normas dinámicas, que es la que enlaza la sucesión mediante un procedimiento como la previsión de conexiones.

En esta perspectiva del proceso, este ha servido en la historia de toda sociedad como mecanismo de comunicación y resolución de estas dicotomías relacionales sociales básicas, por un lado, y por otro, en donde se produce la semiosis ${ }^{4}$ procesal.

Desde el inicio del derecho, entendido este como una construcción propia del mundo occidental, en un principio fueron los pontífices quienes tendieron los puentes entre el Olimpo y el mundo terrenal, a través de la jurispruedentia, como los intérpretes del correcto mensaje de los dioses para los hombres que luego constituiría el derecho. Posteriormente, el proceso sirvió como el escenario para que se dramaticen esos mensajes ${ }^{5}$. Cambiaron los dioses del Olimpo por la fe cristiana, luego sobrevino el culto a la ley, posteriormente la reverencia a la constitución negativa y ahora la veneración a la constitución programática basada en la ideología de los derechos humanos ${ }^{6}$.

1 SUMARIA, Omar. Introducción al derecho a la tutela jurisdiccional. Lima: Ara, 2013. En parecido sentido LÓPEZ, Sergio. «El proceso como espacio de encuentro entre lo social y lo jurídico. Una aproximación de sociología del derecho». En Libro Homenaje a Jorge Barrera Graf. Volumen II. México D. F.: Instituto de Investigaciones Jurídicas de la UNAM, 1989; pp.1015-1038. También BOTTO, Hugo. La congruencia procesal. Principio base para una teoría general del procedimiento civil. Santiago: Editorial de Derecho, 2007.

2 Ibáñez de Aldecoa, Alfonso. Meditaciones sobre la cientificidad dogmática del derecho procesal. Buenos Aires: Ediciones Arayu, 1954, p. 26.

3 Es el engranaje entre la autonomía versus la integración, que es la dicotomía relacional moderna entre el individuo y la comunidad, y la separación versus la acomodación, que es la dicotomía relacional moderna entre los poderes públicos y de facto hacia la consecución de una pluralidad unitaria. SÁNCHEZ-BAYÓN, Antonio. Manual de sociología jurídica estadounidense. Del poder, lo sagrado y la libertad en la Modernidad Occidental. Madrid: Publicaciones Delta, 2009, p. 11.

4 En términos de Samaja por «semiosis» se entiende las consecuencias que tiene la «teoría del signo» sobre la «teoría del dato», en tanto, que el signo no es sólo un instrumento para hablar de los objetos, sino que los objetos mismos están integrados por signos. SAMAJA, Juan. Semiótica y diálectica: Seguido de la Lógica Breve de Hegel. Buenos Aires: JVE Ediciones, 2000; p. 26.

5 Para Antoine Garapon, el proceso es como un espectáculo sujeto a las tres unidades del teatro clásico: espacio, tiempo y acción. GARAPON, Antoine. L'Ane portant des reliques. Essai sur le rituel judiciare. París: Le Cnturión, 1985.

6 Señala Gregorio Robles "que el concepto "derechos humanos" es un concepto político y no técnico, y no puede ser otra cosa. Y como tal concepto político está en función de la 
Por ello, la necesidad del proceso como espacio de encuentro entre lo social y lo jurídico se encuentra en ser un mecanismo adecuado de conexión de lo ideológico con lo pragmático cumpliendo esa función simbólica ritual $^{7}$ en cada etapa de la sociedad y la cultura.

En el contexto actual, dominado por una ideología basada en derechos humanos que son el sustrato de las actuales constituciones, las altas cortes o tribunales constitucionales se convierten en los otroras intérpretes de los mensajes divinos, y a través de ellos se deben hacer valer las promesas que contienen estas «constituciones». Y para llegar a ellos deben existir los mecanismos adecuados que conecten esa «justicia ordinaria» de la corrección de la praxis, es decir, en donde se produce la semiosis procesal, con esa «justicia constitucional» basada en valores y principios en donde se resuelve la dicotomía de las relaciones sociales básicas.

En esta línea de ideas del proceso como fenómeno total o espacio de encuentro en lo social y jurídico, el análisis de sus instituciones no solo debe realizarse desde un punto de vista procesal tradicional o clásico, ya que resultaría parcial, tampoco desde un punto de vista sociológico, porque los resultados resultarían sesgados, sino que ambos deben conjugar para dar un sentido a este fenómeno total.

En las instituciones procesales como fenómeno total, la construcción de un modelo no es posible más que a partir del postulado esencial de que el fenómeno estudiado presenta las propiedades de un sistema, que presupone:

- que el fenómeno está constituido de elementos que tienen relación de interdependencia.

- que la totalidad del fenómeno no puede reducirse a la suma de sus elementos.

- que las relaciones de interdependencia entre los elementos y la totalidad que resulta están controlados por reglas que pueden expresarse en términos lógicos.

lucha política: sirve —o puede servir — para intentar transformar la realidad o para intentar conservarla, pero no para describirla o conocerla», por ello tienen una funcionalidad polífica para las ideologías en la lucha por el poder o para los sistemas de organización política ya establecidos. ROBLES, Gregorio. Epistemología y derecho. Madrid: Ediciones Pirámide, 1982, p. 254.

7 Garapon propone que el ritual judicial podría ser explicado a través de sus símbolos y propone como estrategia reconstituir la cadena de asociaciones que hacen al símbolo significante. GARAPON, Antoine. Essai sur le rituel judiciaire. Ob. cit. 
Sobre dichos supuestos el pensamiento sistémico actual propone un enfoque de análisis que identifica elementos de un todo llamado sistema, que reconoce interacciones entre ellos e influencia entre sí (produce modificaciones). El producto del sistema implica efectividad de cada uno de los elementos y de sus interacciones ${ }^{8}$.

De esta manera se propone que en la evaluación de un mecanismo procesal se deben tener en cuenta tres elementos articulados entre sí:

- El órgano o el aspecto político, es decir, cómo se plasman las relaciones o adecuaciones del poder a través de este instituto. El poder es un factor a tener presente, dado que las formas procesales no son neutrales respecto a la competencia entre grupos sociales. Quién decide el conflicto y el medio a través del cual se resuelve beneficiará y periudicará a diferentes sectores de la sociedad'. En otras palabras, en este estadio importa encontrar la unidad del derecho como producto y productor de política, que a través de este órgano y las prácticas del procedimiento intenta "analizar en el espacio lo que hace en el tiempo» ${ }^{10}$ que otros trabajos se ha denominado como la función sincrónica y diacrónica de los tribunales supremos ${ }^{11}$.

- El recurso, o mecanismo de acceso, es el que organiza el espacio y tiempo, así como las prácticas asimilables a un ritual que se dan dentro del proceso. Determina los actos, conductas, prescripciones y símbolos cuyo cumplimiento, sancionado o no, se convierte en obligatorio por el derecho. Estas variables del procedimiento o del mecanismo se orientan en tres momentos: la constitución del proceso o entrada y define en función de qué o cuáles elementos y actores se establecen o constituyen el espacio del proceso. El debate o núcleo, que articula la estructura y el procedimiento. Y, finalmente, la decisión o salida, que implica las reglas de clausura del debate y salida del espacio del proceso ${ }^{12}$.

- El interés, en tanto, que un diseño procesal puede penetrar solo aspectos individuales o particulares o enfocarse hacia el interés social en general, y que constituye el objeto mismo del proceso y le da su intensidad, tratando de establecer en función de quién o quiénes se define el

8 SUMARIA, Omar. Ob. cit. p. 269.

9 CHASE, Oscar. Derecho, cultura y ritual. Sistemas de resolución de controversias en un contexto intercultural. Trad. Fernando Martín. Madrid: Marcial Pons, 2013; p. 23.

10 GARAPON, Antoine y loannis PAPADOPOULOS. Juzgar en Francia y Estados Unidos. Cultura jurídica francesa y common law. Trad. Viviana Díaz. Bogotá: Legis, 2008; p. 19.

11 SUMARIA, Omar. Casación: Diacronía y sincronía en el derecho. En Revista Peruana de Derecho y Literatura. Lima: Grijley, 2009; p. 227.

12 LÓPEZ, Sergio. Ob. cit. p. 1034. 
interés del asunto; cuál es su característica (económica, política, social, jurídica, etc.), cuál es su importancia relativa (en un proceso, en un conjunto de procesos o en la totalidad de los procesos de una sociedad en un momento dado) y si el interés es el objeto necesario de un proceso, o puede ser resuelto a través de otras instituciones ${ }^{13}$.

Planteado de esta forma el modelo del proceso como fenómeno total, se puede intentar revisar el mecanismo denominado «recurso de agravio constitucional» ante un órgano denominado "Tribunal Constitucional» y el «interés» que promueve este mecanismo. En palabras de Andrés de la Oliva, «el quehacer científico-jurídico debe establecer los conceptos, perfilados con precisión, de modo que cumplan una función de entendimiento de la realidad, de comunicación entre las personas interesadas en esa realidad y —esto ha de subrayarse - de instrumentos máximamente adecuados para resolver los problemas detectados» ${ }^{14}$.

\section{Breve análisis de la naturaleza del recurso de agravio constitucional}

La Constitución de 1979 creó el Tribunal de Garantías Constitucionales y diseñó un mecanismo de casación para el acceso a este contra las resoluciones denegatorias en los procesos de amparo y habeas corpus ${ }^{15}$. Luego, en la Constitución de 1993 fue reemplazado por el «recurso extraordinario» $^{16}$. Finalmente, el Código Procesal Constitucional vigente desde el 2004 estableció como mecanismo de acceso al Tribunal Constitucional (en adelante, TC) al «recurso de agravio constitucional».

Este cambio de nomenclatura no solo es un cambio de rótulo, sino todo un cambio genético en la articulación de los tres componentes mencionados, con relación al determinado contexto cultural. Si la articulación cohesiona, pues funcionaría el recurso; por el contrario, si dichos elementos compiten o difieren entre sí, el mecanismo no cumplirá su función ritual simbólica como mecanismo de conexión entre la «justicia constitucional» y la »justicia ordinaria».

13 LÓPEZ, Sergio. Ob. cit., p. 1033.

14 DE LA OLIVA, Andrés. Objeto del proceso y cosa juzgada en el proceso civil. Navarra: Thomson Civitas, 2005; p. 26.

15 Inciso 2 del artículo 298 de la Constitución Política del Perú 1979

Conocer en casación de las resoluciones denegatorias de la acción de habeas corpus y la acción de amparo agotada la vía judicial.

16 Ley Orgánica del Tribunal Constitucional. 
La diferencia entre recursos extraordinarios y recursos de agravio $u$ ordinarios ya la establece la doctrina procesal clásica. Así, Carnellutti ${ }^{17}$ diferencia los medios impugnativos, señala que en los ordinarios la decisión tiene una doble eficacia, por un lado negativa que produce la rescisión de la sentencia anterior, y por otro lado, una eficacia positiva que produce la sustitución de la resolución recurrida, mientras que en los medios impugnatorios extraordinarios se limitan a la rescisión, o eficacia negativa de la sentencia recurrida con el poder del iudicium rescidems.

Por su parte, Calamandrei ${ }^{18}$ hace la distinción entre medios de gravamen (que serían los ordinarios) y acciones impugnativas (recursos extraordinarios). Así, los medios extraordinarios o de impugnación tienden a quitar vigor al fallo ya formado en cuanto aparezca viciado por determinados defectos que lo hagan anulable. Con esta acción se lleva ante el juez la cognición de una diversa controversia referente a la existencia del vicio que es título para la anulación del fallo. Con la acción de impugnación un reexamen se puede lograr mediatamente, cuando se llegue a obtener la anulación de una sentencia precedente.

Señala el mismo autor que mientras que el medio ordinario o de gravamen es un instituto exclusivamente procesal, vinculado con el principio de pluralidad de instancias que provoca el examen inmediato de la misma controversia en una nueva fase procesal, cuya apertura impide que el pronunciamiento emitido en la fase precedente pase en cosa juzgada. El medio típico ordinario es la apelación. El juez de apelación está llamado a juzgar de inmediato ex novo.

Otros autores sostienen la diferencia en los medios impugnatorios en virtud de su finalidad, por cuanto, los recursos extraordinarios tienden más a salvaguardar el interés público o la primacía del derecho objetivo que proteger el interés particular del recurrente que corresponde a los recursos ordinarios.

Vescovi ${ }^{19}$ por su parte define al recurso extraordinario como:

- El medio impugnativo extraordinario que solo se concede en casos extremos.

- Tiene formalidades especiales.

17 CARNELLUTI, Francesco. Instituciones de derecho procesal civil. Tomo II. Buenos Aires: Ediciones Jurídicas Europa-América, 1952; p. 182.

18 CALAMANDREI, Piero. Estudios sobre el proceso civil. Trad. Santiago Sentís. Buenos Aires: Editorial Bibliográfica Argentina, 1945; pp. 439 y siguientes.

19 VESCOVI, Enrique. Los recursos judiciales y demás medios impugnativos en Iberoamérica. Buenos Aires: Ediciones De Palma, 1988; p. 217. 
- Se refieren a causales taxativamente enumeradas.

- Determina en el órgano decisor facultades excepcionales.

El gravamen o agravio existe cuando se presenta una diferencia entre lo pedido al juez y lo que este nos concede, y cuando esta diferencia nos perjudica. Este gravamen no solo es material o se refiere a la distinta manera de entender la aplicación de la norma al caso concreto, sino que existe gravamen cuando la diferencia de lo pedido y de lo conseguido se concreta a cuestiones o peticiones de orden procesal ${ }^{20}$.

En términos de De la Oliva, la apelación de la sentencia respecto al objeto del proceso de primera instancia tiene ciertas particularidades en cuanto no es ni puede ser enteramente diferente del objeto de la primera instancia $y$, por otro, que tampoco es exactamente el mismo objeto. "Porque, para el objeto del procesal de segunda instancia, es de reconocer que las pretensiones son principalmente impugnatorias de la resolución judicial recurrida en apelación. No son pretensiones directas de tutela, sino pretensiones de tutela moduladas por expresarse una sentencia anterior» ${ }^{21}$.

Así, el objeto necesario del proceso en segunda instancia está constituido por la pretensión impugnatoria del apelante frente a una sentencia total o parcialmente absolutoria o condenatoria recurrida por el primitivo demandante o demandado para que se le otorgue lo que se ha negado en primera instancia o se revoque los pronunciamientos de condena. En ambos casos, salvo que la apelación se funde en infracciones procesales cometidas en la sentencia, no es atendible la variación de los sujetos y de la causa de pedir respecto de lo que fue el objeto procesal de la primera instancia. Sin embargo, es atendible una variación (innovación) en el aspecto fáctico de la causa de pedir en el caso de hechos que no hubieran podido hacerse valer en primera instancia. Y si tales hechos resultan subsumibles en normas que no se alegaron en primera instancia, cabrá también una variación en la faceta jurídica de la causa petendi ${ }^{22}$.

En tal sentido, la mayor relevancia práctica entre medio de impugnación o de gravamen radica en la constitución del agravio y los poderes que se otorgan al órgano judicial a quien se somete el conocimiento y decisión del recurso, dado que en estos últimos las sentencias sometidas a un medio de gravamen la parte que interpone el recurso solicita una nueva sen-

20 CORTES, Valentín. «El problema de la instancia única. Presentación o no de nuevas excepciones y pruebas en segundo grado de jurisdicción». Acta del I Congreso Nacional de Derecho Procesal. Madrid; 1950.

21 DE LA OLIVA, Andrés. Ob. cit. p. 30.

22 DE LA OLIVA, Andrés. Ibid. p. 31. 
El reCURSO de AGRAVIo CONSTITUCIONAL... ¿UN NUEVO MODELO?

tencia ajustada a sus pretensiones, por considerar que la que es objeto de impugnación le causa un perjuicio. Por eso el juez que conoce del medio de gravamen debe tener los mismos poderes frente a la sentencia recurrida, que los poderes que tuvo el juez de instancia; solo así podrá dictarse una sentencia más justa, sin que ello comporte un agravio comparativo respecto de quien adopta la posición de recurrido ${ }^{23}$.

De esta forma el cambio de «recurso extraordinario» que por definición es limitado en cuanto a las resoluciones revisables, los poderes del superior y materias a revisar, es modificado por un «recurso de agravio», es decir, ordinario, ilimitado sobre todo en cuanto a los poderes del juez que promueve inclusive una revisión de hechos en materia «constitucional» y convierte al Tribunal Constitucional en «última y definitiva instancia» tal como se han autodefinido ${ }^{24}$, muy distinto a un órgano casatorio.

\section{El «recurso de agravio constitucional» y el precedente Francisca Vásquez Romero (sentencia recaída en el expediente $n .^{\circ}$ 009787-2014-PA/TC) ¿un nuevo modelo?}

En el precedente Francisca Vásquez Romero (sentencia recaída en el expediente n. ${ }^{\circ}$ 009787-2014-PA/TC), el Tribunal Constitucional ha establecido cuatro motivos específicos para la procedencia del recurso de agravio constitucional, que a saber son a) cuando la supuesta vulneración que se invoca carezca de fundamento; b) cuando la cuestión de derecho contenida en el recurso «no sea de especial trascendencia constitucional»; c) cuando el pedido contradiga un precedente del TC, y d) si ha sido rechazado en casos sustancialmente iguales.

Si bien no es la primera vez que el TC ha desarrollado requisitos procesales para la admisión y procedencia de dicho recurso, más allá de lo previsto por el artículo $18^{\circ}$ del Código Procesal Constitucional, tal como fue en la sentencia recaída en el expediente n. ${ }^{\circ}$ 2887-2005-PHC, nuevamente el TC amplía dichos requisitos de la siguiente manera:

49. El Tribunal Constitucional emitirá sentencia interlocutoria denegatoria cuando:

23 SOLE, Jaime. El recurso de apelación civil. Barcelona: Bosch, 1993; p. 14.

24 El magistrado Blume Fortini, en la sentencia del Tribunal Constitucional recaída sobre el expediente . $^{\circ} 009787-2014-\mathrm{PA} / \mathrm{TC}$, emitió voto singular señalando que "[u]na vez abierta la puerta de acceso al Tribunal Constitucional vía la concesión del recurso de agravio constitucional, lo cual significa acceder a una instancia de grado, que, además es última y definitiva en la jurisdicción nacional (...)». (El énfasis es propio.) 
a) Carezca de fundamentación la supuesta vulneración que se invoque;

b) La cuestión de derecho contenida en el recurso no sea de especial trascendencia constitucional;

c) La cuestión de derecho invocada contradiga un precedente vinculante del Tribunal Constitucional;

d) Se haya decidido de manera desestimatoria en casos sustancialmente iguales.

La citada sentencia se dictará sin más trámite

50. Existe una cuestión de especial trascendencia constitucional cuando la resolución resulta indispensable para solucionar un conflicto de relevancia o cuando se presente la urgencia de una revisión sobre el contenido de un derecho fundamental.

51. De este modo, el Tribunal Constitucional, a la luz de su jurisprudencia, cumplirá adecuada y oportunamente con su obligación de garantizar la supremacía de la Constitución y el efectivo respecto de los derechos fundamentales. Preservará así, la autoridad que le ha confiado el pueblo a través del Congreso de la República.

Más allá de la discusión, pero no menos importante, si el TC podía por sí mismo y vía jurisprudencial modificar o ampliar los requisitos de admisibilidad y procedencia del recurso de agravio constitucional, estos requisitos agregados por el TC en esta sentencia para la procedencia del recurso de agravio constitucional son materia de debate por distintos motivos. Sin embargo, el supuesto que ha despertado mayor polémica es aquel que rechaza el recurso de agravio constitucional cuando «no sea de especial trascendencia constitucional» inspirado obviamente en la reforma de la LOTC del TC de España, que ya bastantes debates ha generado ${ }^{25}$.

En este sentido, $\mathrm{Abad}^{26}$ relata que en el escenario peruano algunos lo entienden como «un certiorari criollo y sui generis» ${ }^{27}$, y dentro del mismo TC

25 Por citar algunos ejemplos CRUZ, Pedro. «El recurso de amparo constitucional. El juez y el legisladon. En CRUZ, Pedro, JIMÉNEZ, Javier, LÓPEZ, Luis y Pablo PÉREZ. Los procesos constitucionales (Segundo Simposio de Derecho Constitucional). Madrid: Centro de Estudios Constitucionales, 1992; p. 119; FIGUERUELO, Ángela. El recurso de amparo: estado de la cuestión. Madrid: Biblioteca Nueva, 2001; p. 73 y SENÉS, Carmen. La vía judicial previa al recurso de amparo. Madrid: Civitas, 1994, nota al pie 112; pp. 67-71; PÉREZ Pablo. El recurso de amparo. Ob. cit., pp. 262-263 y REQUEJO, Juan. Hacia la objetivación del amparo constitucional (Comentario al Auto de la Sala Primera del Tribunal Constitucional de 19 de septiembre de 1994). En Revista Española de Derecho Constitucional n. ${ }^{\circ} 42,1994$; pp. 159-160.

26 ABAD, Samuel. «El acceso al Tribunal Constitucional a través del recurso de agravio constitucional. Un balance necesario: diez años después». En GRÁNDEZ, Pedro (coordinador). El debate en torno a los límites al recurso de agravio constitucional. Lima: Palestra, 2014; p. 35.

27 GARCÍA, Domingo. «Entre la Constitución y la Ley. Una delgada línea divisoria que rara vez se aprecia». En V Congreso Nacional de Derecho Procesal Constitucional. A diez años 
entienden «que no se trata del ejercicio de una abierta discrecionalidad que, por ejemplo, es más propia del modelo anglosajón» ${ }^{28}$, lo que implica que se estaría ante un nuevo modelo si no impreciso por lo menos ambiguo.

En el análisis de este presupuesto, en principio se debe tener en cuenta que en nuestro sistema jurídico la tutela de los derechos ha sido encomendada tanto a los jueces y tribunales ordinarios como al TC, lo que es denominado «tutela multinivel» ${ }^{29}$ y que la articulación entre sus respectivas competencias sobre la materia se rige por el principio de subsidiariedad. En consecuencia, es lógico que las propuestas de reforma estuvieran dirigidas tanto al recurso de amparo y sus mecanismos de acceso al TC, así como a los mecanismos de tutela judicial de los derechos.

Luego, la idea de la confluencia de una multiplicidad de catálogos de derechos y de órganos jurisdiccionales encargados de su fiscalización puede resultar muy atractiva desde la perspectiva de la efectiva protección de los derechos del particular. Sin embargo, los riesgos han sido siempre manifiestos. La eficacia de una especie de sistema de tutela multinivel de los derechos pasa necesariamente por el cumplimiento de sus funciones por cada uno de los actores implicados. Un inadecuado reparto de papeles pondría en peligro la eficacia de la aplicación práctica de la tan reivindicada multilevel protection of human rights.

En consecuencia, se trata de contrastar si en una especie de sistema de tutela multinivel entre justicia constitucional y justicia ordinaria, todos y cada uno de los actores implicados desempeñan las funciones que naturalmente les corresponden en la protección jurisdiccional de los derechos del par-

de vigencia del Código Procesal Constitucional. Arequipa: ADRUS, 2013; p. 30. Cit. ABAD, Samuel. Ob. cit. p. 35

28 ESPINOSA-SALDAÑA, Eloy. «Acceso a los jueces y juezas constitucionales y ejercicio de sus competencias en los procesos de constitucionalidad de la libertad dentro de las pautas previstas por el Código Procesal Constitucional. Reflexiones al amparo de lo resuelto en la sentencia emitida en el caso Francisca Vásquez Romero». En V Congreso Nacional de Derecho Procesal Constitucional. A diez años de vigencia del Código Procesal Constitucional. Arequipa: ADRUS, 2013; p. 106. cit. ABAD, Samuel. Ob. cit. p. 35.

29 Indica Santiago Martínez-Vares García como tutela multinivel de los derechos fundamentales que «La garantía de los derechos fundamentales en el moderno Estado constitucional se encuentra esencialmente asegurada a través de la inserción en el propio texto constitucional de un catálogo de derechos fundamentales y a través del establecimiento y previsión de mecanismos de garantía de los mismos por parte de la jurisdicción ordinaria y de la jurisdicción constitucional». Sin embargo, en los últimos tiempos, la garantía de derechos también se viene promoviendo a través de la incorporación de los diversos Estados a nuevos procesos de integración, que han dado lugar a catálogos distintos de derechos fundamentales con su correspondiente sistema de garantía. MARTÍNEZ-VARES, Santiago. "La tutela multinivel de los derechos fundamentales». En XVI Reunión trilateral de los Tribunales Constitucionales de Italia, Portugal y España. Santiago de Compostela, del 16 a 18 de octubre de 2014. 
ticular en el nivel nacional. De esta manera, la nueva regulación del recurso de amparo constitucional a través del precedente Francisca Vásquez Romero (sentencia recaída en el expediente n. $\left.{ }^{\circ} 009787-2014-P A / T C\right) ~ h a$ iniciado un objeto de intenso debate.

En nuestro caso, la tutela - digámoslo así-, visible de los derechos y libertades fundamentales, ha correspondido principalmente al TC desde la puesta en funcionamiento del sistema constitucional democrático. Sin embargo, en respuesta a ello se ha producido una manifiesta saturación de dicho Tribunal generada por la llamada «crisis de éxito» en la protección de los derechos debido al excesivo protagonismo de este órgano en esta función, en tanto, se toma como presupuesto que los jueces y tribunales nacionales no desempeñan de forma eficaz el rol que les corresponde como garantes naturales de los derechos.

Por esta razón, la fase de admisión o acceso al TC es, sin duda, determinante en la configuración del recurso. Al fin y al cabo, las posibilidades de éxito de una demanda dependen en buena medida del carácter más o menos estricto del contenido de las condiciones de admisión. Por tanto, se pretende, por un lado, determinar las consecuencias prácticas para el particular de las reformas de la regulación del trámite de admisión del recurso de agravio constitucional con el fin último de concretar, y, por otro lado, si la articulación de las interconexiones procesales entre dichos mecanismos garantizan una efectiva tutela multinivel de sus derechos y libertades fundamentales en nuestro espacio.

En el caso concreto del recurso de agravio constitucional, la polémica suscitada en torno al nuevo requisito de la especial trascendencia constitucional, se verifica la ausencia de un trabajo exhaustivo y de carácter eminentemente práctico sobre las demandas de amparo y el volumen de asuntos pendientes en el TC. En definitiva, el objetivo sería analizar qué se ha perseguido con la reforma ${ }^{30}$, cuáles pueden ser los resultados y qué consecuencias puede tener para la efectiva protección jurisdiccional de los derechos desde la perspectiva del acceso del particular a estas concretas garantías.

Se podría inferir que la Constitución de 1979 atribuyó al TC en principio su función de garante de los derechos con carácter subsidiario respecto de

30 Que muy escuetamente se precisa en el precedente en cuestión «51. De este modo, el Tribunal Constitucional, a la luz de su jurisprudencia, cumplirá adecuada y oportunamente con su obligación de garantizar la supremacía de la Constitución y el efectivo respecto de los derechos fundamentales. Preservará así, la autoridad que le ha confiado el pueblo a través del Congreso de la República». 
la protección dispensada por los órganos de la jurisdicción ordinaria. Sin embargo, en la Constitución de 1993, el TC ha sido el protagonista indiscutible en cuanto a la protección jurisdiccional de los derechos desde su puesta en funcionamiento. A esta situación contribuyeron diversos factores que acabaron por relegar a un segundo plano a quienes fueron concebidos como garantes naturales de los derechos de las personas, es decir, los jueces y tribunales ordinarios.

La continuidad en la abusiva utilización del recurso de amparo tras la entrada en vigor de la Ley n. 23506 y del posterior Código Procesal Constitucional no tardó en abrir el debate sobre la conveniencia o no de su objetivación. Así con el fin último de aliviar la insostenible carga de trabajo del TC, ésta estuvo encaminada a restringir el acceso a la jurisdicción constitucional de quienes de la misma pretenden la reparación de presuntas vulneraciones de sus derechos y libertades fundamentales. Se trata así de determinar si este precedente ha supuesto un cambio en el modelo de recurso de amparo constitucional y las consecuencias prácticas para la efectiva protección de los derechos del particular.

En principio se debe tener en cuenta que el recurso de amparo constitucional no es un elemento consustancial a un sistema de justicia constitucional, concentrado o no. En el caso del ordenamiento jurídico pervano, la presencia de este mecanismo es resultado de la fuerte concepción garantista con la que el constituyente dio cabida a los derechos en la Constitución de 1979 y posterior Constitución de 1993, y a la generalizada desconfianza frente a los jueces y tribunales de la jurisdicción ordinaria en el periodo de la transición democrática y de una cierta «cultura de amparo» y «constitucionalismo» que, importada del constitucionalismo latinoamericano y europeo, se introdujo en nuestra propia tradición histórica, a través de la Constitución española de 1978.

Así, mientras que la «hipótesis de la imitación» y la tradición histórica ayudan a entender el porqué de la inclusión del recurso de amparo, la razón que justifica jurídicamente su presencia en nuestro ordenamiento es, sin duda, la posición dominante que los derechos y libertades fundamentales vinieron a ocupar en la Constitución democrática. Sin embargo, la finalidad última del recurso de amparo no es la depuración del ordenamiento jurídico en el sentido apuntado y, por tanto, su presencia no es exigida para garantizar la efectividad de la Constitución.

Citando a Bellamy ${ }^{31}$, respecto de este fenómeno de «constitucionalismo» y justicia constitucional:

31 BELLAMY, Richard. Constitucionalismo político. Una defensa republicana de la constitucionalidad de la democracia. Trad. Jorge Urdanu y Santiago Gallego. Madrid: Marcial Pons, 2010; p. 17. 
La tesis crecientemente dominante establece que las constituciones consagran y aseguran los valores fundamentales de una sociedad democrática, lo cual es entendido como el Constitucionalismo Legal, en donde la Constitución se entiende como un documento escrito que es superior a la legislación ordinaria y que se encuentra protegida contra cambios legislativos, que ha de ser interpretada por el Poder Judicial o una Alta Corte o un Tribunal Constitucional, y que es parte integrante del sistema legal y político, y se asume que es la base para que los ciudadanos sean tratados de un modo democrático, como merecedores de igual preocupación y respeto.

Pero, las constituciones hacen mucho más que proteger derechos, no obstante, nada ha sido tan decisivo para que el constitucionalismo transite por el pensamiento legal y no por la del político como la plasmación de derechos en un documento constitucional, su interpretación o elaboración por parte de un Tribunal Supremo o Constitucional y el constante énfasis en ellos.

El comprometerse con los derechos no quiere decir que su protección requiera plasmarlos en una declaración de derechos que deba ser supervisada por un Tribunal Constitucional; sin embargo, esta posición se halla sustentada en los siguientes argumentos: a) se afirma que fijar ciertos derechos sujetos a revisión judicial protege contra la tiranía e incompetencia de la mayoría; b) la integridad de la ley depende de los derechos y, en ese sentido, se asume que los derechos proveen de los principios necesarios para que los jueces orienten su criterio hacia una decisión consistente con los valores básicos que subyacen a todo el sistema legal; c) se dice que ciertos derechos se hallan implícitos en el proceso democrático.

De esta manera el recurso de amparo nace como un mecanismo adicional de protección de los derechos y libertades, de carácter extraordinario y subsidiario. A pesar de estas características, parecen haber hecho caso omiso tanto sus beneficiarios como el propio TC. Las consecuencias eran previsibles. El abuso del recurso de amparo constitucional ha situado al TC al borde del colapso y, frente a esta situación, una de las soluciones más factibles era, sin duda, limitar el acceso por esta vía a la jurisdicción constitucional limitando el recurso de agravio constitucional.

En el caso del derecho comparado, el desarrollo normativo del amparo mexicano puso de manifiesto, hace ya casi un siglo, las dificultades que en términos de carga de trabajo supondría la inclusión en su objeto de actos judiciales. Por su parte, el originario Tribunal del Imperio austriaco practicó la inadmisión de la demanda cuando de un examen a limine se pudiera deducir una insuficiente expectativa de éxito o el insuficiente interés del 
caso para resolver una cuestión de alcance constitucional. Como se verá, el recurso de amparo frente a actos y omisiones de los jueces y tribunales ordinarios ha supuesto uno de los principales desafíos para el TC. Además, la inadmisión de la demanda a limine por falta de expectativa de éxito fue la primera vía a través de la que se pretendió limitar el acceso del particular al recurso de amparo en la tradición de la democracia española que luego hemos heredado.

En este orden de ideas, la cuestión de la obstaculización del acceso en base al interés del recurso para resolver una cuestión de alcance constitucional es de la mayor importancia pues, al menos en teoría, ésta fue la opción por la que se decantó el legislador español de 2007 para reducir el volumen de trabajo del Alto Tribunal español y que ha tomado como fuente el TC peruano.

En cualquier caso, y sobre todo por una cuestión de contextualización histórica, resulta de interés un somero repaso a la evolución de la regulación de cada uno de estos modelos.

Durante sus primeros años de vida, el TC estuvo determinado en su actividad por los recelos suscitados por una judicatura viciada por su pasado y por la necesidad de inyectar contenidos constitucionales a un sistema democrático en ciernes. Sin embargo, a mediados de la década de los ochenta, comenzó a evidenciarse el riesgo de una muerte por éxito. El desafío resultaba todavía asumible y tanto el legislador como el propio TC se mostraron especialmente cautos.

Como se ha advertido, el protagonismo alcanzado por el TC en cuanto a la protección de los derechos y libertades fundamentales respondió, al menos en un primer momento, a las condiciones estructurales y de orden subjetivo que presidieron la transición democrática: desconfianza hacia una judicatura escasamente imbuida en los valores constitucionales y falta de un cuerpo jurisprudencial capaz de guiar a la justicia ordinaria en el ejercicio de sus funciones como garante natural de los derechos y libertades.

Pero, superados los primeros años de democracia y empapado el sistema jurídico de los nuevos valores constitucionales, correspondía ya hacer efectivo el carácter subsidiario de la protección dispensada por el TC frente a la que constitucionalmente corresponde a los órganos de la jurisdicción ordinaria.

Lejos ya de las incertidumbres de los primeros años de la transición democrática, resultaba ineludible identificar las causas que seguían impulsando el recurso a la jurisdicción constitucional como si de una última instancia procesal en materia de derechos se tratara. Entre otros motivos, una posi- 
ble insuficiencia de la protección dispensada por los jueces y tribunales ordinarios y una difícil delimitación competencial entre ambas jurisdicciones en materia de derechos y libertades fundamentales, podrían considerarse dos de los factores determinantes del abuso del recurso de amparo constitucional en los años siguientes.

En cuanto a la reforma de los mecanismos de tutela judicial ordinaria, buena parte de la doctrina se mostró a favor de una simplificación de los cauces procesales para la protección de los derechos fundamentales ante los tribunales ordinarios con un refuerzo paralelo de los instrumentos accionables en dicha vía para reparar los errores in procedendo sin necesidad de recurrir al amparo constitucional.

También fue debatida la posibilidad de establecer un recurso rescisorio. En dicho aspecto, el Tribunal Constitucional, en la sentencia recaída en el expediente n. ${ }^{\circ}$ 3070-2013-AA, para el proceso de amparo, ha desarrollado el concepto de cuándo una vía puede ser considerada «igualmente satisfactoria» a efectos de restringir el amparo por la presencia de una vía igualmente satisfactoria.

No obstante, de mayor calado fueron las propuestas centradas en la necesidad de reformar la regulación jurídico-procesal del propio recurso de amparo, y ello no solo por los efectos que la sobrecarga de trabajo suponía para la tutela de los derechos y libertades fundamentales, sino también, y sobre todo, por la afectación del normal desempeño de aquellas otras funciones que, por su ejercicio en régimen de monopolio, no pueden ser sino consideradas como las propias del TC: el control de constitucionalidad de las leyes y los conflictos competenciales.

En dicha línea de argumentos, fueron las propuestas dirigidas a restringir el acceso al recurso de agravio constitucional reforzando su dimensión objetiva, y ello con el fin último de afrontar el excesivo tiempo empleado en los recursos de escasa o nula relevancia constitucional. El debate se centró en torno a dos modelos posibles, uno próximo al modelo de selección de casos del writ of certiorari norteamericano y una suerte de «modelo mixto», inspirado en la reforma de 1993 de la Ley Orgánica del Tribunal Constitucional Federal alemán.

El mismo debate se presenta con relación a la función de la Corte Suprema, así:

En esta supuesta renovación del recurso de casación del Código Procesal Civil se han presentado distintas alternativas desde las que proponen una modificación legislativa, en cuanto al trámite, las causales 
o los fines, hasta las que promueven el cambio o supresión de la institución. Así por ejemplo, se señala que la Corte de Casación debería tener acceso al conocimiento de hechos en caso de arbitrariedad en materia probatoria y eliminar el efecto suspensivo o limitarlo solo a las sentencias expedidas en procesos de trámite plenario o abreviado, o la introducción del «certiorari» como facultad discrecional de la Corte Suprema de asumir competencia casatoria en relación a determinados procesos. Recientemente la Academia de la Magistratura ha reunido los documentos con relación a la modificación del recurso de casación entre los años 2001-2012 a través del profesor Juan Monroy Gálvez.

De todas estas propuestas, el objetivo ha sido la disminución cuantitativa de la carga procesal de la Corte Suprema a través de mecanismos de limitación ya sea legal (tipos de procesos) o discrecional (certiorari), sobre la base de la creación de una jurisprudencia vinculante. Sin embargo, es ahí donde radicaría el problema, se pretende estructurar un mecanismo mixto que articule el «certiorari» y el control de legalidad, sin entender propiamente el concepto de «jurisprudencia vinculante» como soporte de este modelo ${ }^{32}$.

Por ello, se decantó por un modelo que hiciera patente la confluencia en el recurso de amparo constitucional de sus dos vertientes, la subjetiva y la objetiva, aunque con especial interés en reorientar los esfuerzos de la admisión hacia la protección objetiva de la Constitución, la negativa a las propuestas que reclamaban la implantación de un modelo discrecional fue la tendencia generalizada, llegando al modelo presente. Tal como indica Abad «la intención de quienes han introducido este motivo de impugnación no ha sido objetivar al cien por ciento al proceso de amparo sino mantener una tutela subjetiva. Es decir, parecería que se ha acogido a una interpretación mixta (objetiva-subjetiva)»33.

A manera de conclusión, transcurridos ya más de treinta años de ejercicio de la jurisdicción constitucional no tenía mucho sentido mantener el modelo originario de recurso de amparo, al menos como en un primer momento lo entendieron tanto los operadores jurídicos como el propio TC. La Constitución hace descansar la tutela primera de los derechos en los órganos de la jurisdicción ordinaria. Por ello, a la hora de determinar el alcance de este precedente, no debieran perderse de vista ni los motivos que impulsaron al constituyente a incorporar el recurso de amparo como

32 SUMARIA, Omar. La casación como modelo racional en la construcción del precedente vinculante. En Revista Gaceta Civil \& Procesal Civil. Tomo 18. Lima: Gaceta Jurídica, Diciembre 2014 ; pp. 49-62.

33 ABAD, Samuel. Ob. cit. p. 35. 
garantía jurisdiccional de los derechos, ni las causas que incentivaron su abusiva utilización, ni, por tanto, el estado actual de la justicia ordinaria. Y preguntándonos si al día de hoy, ¿existe un nuevo modelo de recurso de amparo constitucional? Si es así, ¿cuáles son las consecuencias del «nuevo amparo» para la protección jurisdiccional de los derechos del particular? En concreto, ¿se ha restringido el acceso a la jurisdicción constitucional? En ese caso, ¿se ha procedido al preceptivo refuerzo de la protección dispensada por los órganos de la jurisdicción ordinaria? ¿Están los jueces y tribunales ordinarios en la mejor situación para afrontar las consecuencias de una restricción del acceso al TC vía recurso de agravio constitucional? 